Canadian

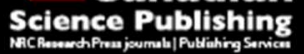

Canadian Journal of Civil Engineering Revue canadienne de génie civil

\title{
Analysis and Strengthening of Caisson Foundations for Uplift Loads
}

\begin{tabular}{|r|l|}
\hline Journal: & Canadian Journal of Civil Engineering \\
\hline Manuscript ID & cjce-2015-0350.R1 \\
\hline Manuscript Type: & Article \\
\hline Date Submitted by the Author: & 20 -Jan-2016 \\
\hline Complete List of Authors: & $\begin{array}{l}\text { Guner, Serhan; University of Toledo, Civil Engineering } \\
\text { Carriere, Jean; Morrison Hershfield Limited }\end{array}$ \\
\hline Keyword: & deep beams, micro piles, nonlinear analysis, retrofit, strut-and-tie method \\
\hline
\end{tabular}


Analysis and strengthening of caisson foundations for uplift loads

Serhan Guner and Jean Carrière

Serhan Guner: Department of Civil Engineering, University of Toledo, Toledo, OH 43606, USA

Jean Carrière: Morrison Hershfield Limited, Toronto, ON L3T 7W4, Canada

Corresponding Author:

Serhan Guner, Ph.D., P.Eng.

Assistant Professor

Department of Civil Engineering

University of Toledo

2801 W Bancroft St. MS 307

Nitschke Hall 3021

Toledo, OH 43606-3390

P: 419-530-8133

$\mathrm{W}$ : www.utoledo.edu/engineering/faculty/serhan-guner

E: serhan.guner@utoledo.edu 


\begin{abstract}
Many existing self-supporting towers are built with constant-width caisson foundations. Due to the increased demand to add more antennas to the towers, and more stringent strength requirements in recently revised design standards, many existing caisson foundations require significant strengthening for additional uplift resistance. Although a number of retrofit design solutions are frequently used in practice, there is a lack of literature providing guidelines for the proper analysis of retrofitted foundations. This study proposes a detailed analysis and design methodology to significantly increase the uplift capacity of existing caissons through the use of helical micro piles and reinforced concrete cap beams. Strut-and-tie models are developed and nonlinear finite element analyses are undertaken to verify the behaviour of the proposed design. The overall design methodology is presented in a case study involving an existing tower. The proposed design has a general applicability and is suitable for applications where there is limited space around the existing foundations.
\end{abstract}

Keywords: caisson foundations, deep beams, finite elements, micro piles, modeling, nonlinear analysis, retrofit, strut-and-tie method, towers, uplift loads. 


\section{Introduction}

New wireless technologies, such as LTE and 4G networks, have created an increased demand for new telecommunication installation in the last decade. Due to high costs of installing new towers and of purchasing land (especially in and around urban areas), it has become more attractive for service providers to co-locate on existing towers - however, many of these towers are at their design capacity. As a consequence, many existing towers require strengthening through reinforcements to support the increased loads. The design of these reinforcements must satisfy the latest version of the CSA S37 standard, which is generally more stringent in strength requirements than the previous editions of the standard. One critical change to this standard has been a reduction in the resistance factor value for caisson foundations which are subjected to uplift loads (see Table 1). A caisson foundation designed at capacity prior to 2001 would be overloaded by a factor of 2.0 according to the 2001 edition of the standard, and by a factor of 1.5 according to the current 2013 edition of the standard. The latest standard has required significant strengthening of many existing caisson foundations, especially those designed prior to 2001 .

Caisson foundations are commonly used for self-supporting towers. These towers are subjected to significant overturning moments, and small axial forces. The overturning moments are resisted by the tensile and compressive resistance of the caisson foundations, as illustrated in Fig. 1. Due to the changing nature of wind direction and pressure, caisson foundations are exposed to cyclic load reversals. Compared to other foundation systems carrying a constant level of axial compression, caisson foundations are subjected to a more complex state of stress. Caissons typically resist the applied compression through skin friction and tip bearing, while the tensile resistance is provided only by skin friction and self-weight of the caisson. Consequently, 
strengthening of an existing caisson presents significant challenges to increase the uplift capacity by a factor in excess of 1.5 .

A number of schemes are commonly employed in industry to increase the uplift capacities of existing caissons. Weight blocks, such as thick concrete slabs, are attached to existing caissons for small overloads, using discontinuous dowel bars developed with epoxybased adhesives. For larger overloads, new anchors, such as micro piles or new caissons, are attached to existing caissons or tower legs. Some examples of the commonly used retrofit schemes are presented in Fig. 2. Although these retrofit schemes are frequently used in industry, there are no known published guidelines for the proper analysis and design of the retrofitted foundation systems. The connections between the existing caissons and the new retrofit elements are particularly critical. If not analysed and designed properly, these retrofits could render an entire design ineffective, which may result in structural failures due to overloads.

The objective of this study is to develop an analysis and design methodology for the retrofit of existing caisson foundations for large uplift overloads. The main focus is to present the detailed numerical analysis studies to provide a general framework for the proposed methodology.

\section{Literature Review}

The literature investigating the behaviour, design, and strengthening of tower structures remain very limited. Magued et al. (1989) presented a concise review of the evolution of the CSA S37 standard from 1954 to 1986, with a particular focus on upgrading the strength levels of existing towers. This study also presented a database that included failures of guyed towers taller than $75 \mathrm{~m}$ located in Canada. Bruneau et al. (1989) proposed a set of guidelines for upgrading 
existing towers, developed from a structural reliability analysis. They indicated that the failure rate for guyed telecommunication towers was generally unacceptably high in Canada. Wahba et al. (1994) analysed 41 guyed towers to justify the load factors to be used in the CSA S37-94 standard. Selby and Dryburgh (1996) conducted a number of comparative studies to determine the conditions under which the patch load analysis of the CSA S37-94 standard was required for guyed towers. Kumalasari et al. (2006) presented the results of an experimental study involving seven solid steel round bracing members strengthened with rods and angles, and proposed a simplified design procedure for the determination of compressive strength of such members. Faridafshin and McClure (2008) examined three existing guyed tower masts and numerically studied the effects of three earthquake records. Yet none of these studies addressed the lack of literature investigating the structural strengthening of tower foundations. One published research paper by Abdalla (2002) presented a case study involving self-supporting and guyed tower foundations, and proposed repair and strengthening solutions. However, no numerical analysis and verification studies were presented for the proposed methods.

\section{Proposed Design Methodology with a Case Study}

The tower examined has a height of $90 \mathrm{~m}$ with a face-width of $12.2 \mathrm{~m}$ at the base, as shown in Fig. 3. The tower is located in a residential area of Toronto, Ontario. It was designed and constructed in the early 1970s. Due to the high demand to add antennas on this tower, the tower mast has been reinforced several times in recent years. The tower has three caisson foundations (one is shown in Fig. 4), each with a diameter of $1067 \mathrm{~mm}, 30$-\#9 longitudinal reinforcing bars, and \#3 circular hoops spaced at $300 \mathrm{~mm}$, as indicated on the original design 
drawings. These drawings also specified a concrete compressive strength of 27.6 MPa, a reinforcing steel yield strength of $414 \mathrm{MPa}$, and a concrete cover of $76 \mathrm{~mm}$.

A detailed tower analysis was conducted for the increased loading. The analysis results indicated the maximum factored uplift and compression reactions to be $1530 \mathrm{kN}$ and $1740 \mathrm{kN}$, respectively, at each caisson. The factored uplift capacity was calculated to be $675 \mathrm{kN}$ using the geotechnical resistance factor of 0.375 in the CSA S37-01 standard. Considering the 136-kN self-weight of the caisson, an overload factor of 2.1 was obtained. Allowing for a $6 \%$ reserve capacity, an additional uplift capacity of $800 \mathrm{kN}$ was required per caisson. To provide such a significant additional resistance, new structural elements, such as new anchors or foundations, should be considered. Due to the limited space available on the tower site, two helical micro piles, each with $400 \mathrm{kN}$ factored tensile capacity, was employed in the proposed design. The design of the micro piles was conducted in a separate geotechnical study and is out of the scope of this paper.

The main structural challenge in using micro piles is the difficulty of creating an effective connection between the piles and the existing caissons while providing the required clearance from the existing caissons. Among a few options, reinforced concrete cap beams emerge as one practical alternative; however, a relatively large depth and width is required to provide the proper space and stability to the micro pile heads. A depth of $1000 \mathrm{~mm}$, which is approximately the same as the existing caisson diameter, and a width of $800 \mathrm{~mm}$ was used in the proposed design. A clear span of $700 \mathrm{~mm}$ from the face of the caisson to the pile head was required by the geotechnical study. These dimensions result in a clear span to depth ratio of 0.7 . Recall that the CSA A23.3-14 standard classifies flexural members as deep members when the clear span to 
depth ratios is less than 2.0, and subsequently requires the use of the strut-and-tie analysis method and strict anchorage requirements for the tension reinforcement.

The following sections present the verification studies using the strut-and-tie method and nonlinear finite element analyses.

\section{Strut and Tie Modeling}

Verification Uplift Forces

A strut-and-tie analysis was employed to verify the overall design and determine the required quantities of reinforcing bars. The strength reduction parameters were taken according to the CSA A23.3-14 standard, and the material properties were obtained from the original design drawings, as listed in Table 2 , where $\varphi_{c}$ is the resistance factor for concrete (taken as 0.65), $m$ is the confinement modification factor (taken as 1.0), $\mathrm{C}$ refers to compression, T refers to tension, $f_{c}{ }_{c}$ is the specified compressive strength of concrete, $f_{y}$ is the specified yield strength of the reinforcement, and $A_{S}$ is the reinforcement area.

The vertical reinforcement of the existing caisson was modelled with six ties, each with 5-\#9 bars. The main tension reinforcement was placed $100 \mathrm{~mm}$ from the top of the beam for a clear cover of $75 \mathrm{~mm}$ and a stirrup bar size of $15 \mathrm{M}$. The total factored leg load of $1530 \mathrm{kN}$ was applied equally over the six nodes at the top of the caisson. The micro pile reactions were considered with two vertical point loads, each with a magnitude of $400 \mathrm{kN}$. The horizontal force component of $1.5 \mathrm{kN}$ due to the pile slope (specified to be less than $5^{\circ}$ ) was neglected in the analysis. The geometry and the internal forces of the strut-and-tie model was determined with the help of a computer program, CAST (Tjhin and Kuchma 2004). An iterative process was employed to determine the geometry of the model and the minimum amount of reinforcement 
required. Hand calculations were performed to determine the capacities of the struts, ties, and the nodal zones according to the CSA A23.3-14 standard. The final model is presented in Fig. 5, where the strut and tie widths are also shown.

The analysis results in the form of unity factors (presented in Fig. 6) suggests that the proposed design is adequate. The maximum stress ratio is 0.98 for the ties, 0.21 for the struts, and 0.25 for the nodes. Despite the low concrete stresses, the width of the beam was kept at 800 $\mathrm{mm}$ due to stability reasons. The limiting component of the design was the main tension reinforcement. In this study, 4-20M bars were used to obtain the minimum required design. It should also be recalled that the design already considers some reserve capacity, the strain hardening behaviour of the reinforcement was not considered, and the strut-and-tie analysis is a conservative, lower-bound solution. Nonetheless, the use of 4-25M may be advisable to reduce the maximum stress ratio to 0.59 , given the negligible change in the construction costs.

In addition, $8-15 \mathrm{M}$ vertical reinforcement was used at the location of the micro pile to transfer the pile tension to the node above (Node 1 in Fig. 5). It should be noted that this reinforcement should be fully developed at Node 1, which can be achieved with a welded plate or a closed stirrup. Two pairs of $15 \mathrm{M}$ stirrups (with four legs each) were used at each side of the pile in this study. Also note that this tie reinforcement was not designed to be at capacity, considering the construction variability and the beneficial effects of additional confinement at this critical location.

\section{Verification for Compression Forces}

There is no need for the strengthening of the caisson for the compression loads for this tower. The maximum factored compression reaction was calculated to be $1740 \mathrm{kN}$, while the existing 
caisson had a factored compression resistance of $2550 \mathrm{kN}$. However, due to the load sharing, the micro piles will carry a part of the total applied compression load and the cap beams will be subjected to positive bending. If no reinforcement is provided at the bottom of the beams, the system will develop a moment release under compression. This will result in cracking at the lower segment of the interface, as shown in Fig. 7. For durability reasons, the positive bending reinforcement is provided in this study. For this purpose, the micro piles were designed to have a minimum compressive load capacity of $400 \mathrm{kN}$, and another strut-and-tie model was developed with two micro pile reactions and the total leg compression applied to the existing caisson. The analysis results indicated that 4-20M bars were sufficient at the bottom of the beams with a stress ratio of 0.98 . Once again, it is advisable to use $4-25 \mathrm{M}$, given the negligible change in the construction costs.

\section{Crack Control Reinforcement}

Minimum horizontal and vertical reinforcement should be placed near the side faces of deep flexural members (see Clauses 10.6.2 and 11.4.5 of CSA A23.3-14). For the horizontal reinforcement, four pairs of $20 \mathrm{M}$ bars were selected to provide the required $1200 \mathrm{~mm}^{2}$ of steel per side with a maximum spacing of $200 \mathrm{~mm}$. For the vertical reinforcement, two legs of $15 \mathrm{M}$ bars with $250 \mathrm{~mm}$ spacing was used to provide the required reinforcement ratio of 0.002 . A closed stirrup was used for this reinforcement, which will also provide confinement and improve the ductility. The resulting reinforcement arrangement is presented in Fig. 8. 


\section{Reinforcement Development at the Nodes}

A critical requirement for the design of deep members is the anchorage of the reinforcement. The tie reinforcement must be capable of resisting the calculated tension at all nodes. For the model developed above, the use of closed stirrups ensured the full development of the vertical $8-15 \mathrm{M}$ bars. For the main tension reinforcement of 4-20M, either a welded plate or a standard $90^{\circ}$ hook is required at Node 1 (in Fig. 5). A standard hook was employed in this study, along with a concrete overhang of $400 \mathrm{~mm}$ beyond Node 1 to fully develop these bars.

The strut-and-tie model developed includes continuous horizontal tie reinforcement. However, installation of continuous bars will not be possible in most cases due to the difficulty in drilling through existing caissons without encountering one of the existing reinforcement bars inside. One practical, and often used, solution is to employ discontinuous bars embedded into the caisson with the use of epoxy adhesives. The embedment length required to develop the bond strength is typically provided by an adhesive manufacturer, which was in the range of $250 \mathrm{~mm}$ for the product that we selected. It should be noted that using the bond development length recommended by a manufacturer will not ensure that the required bar tension can be successfully carried. An additional reinforcing bar system is typically required to transfer the applied tension to a support or other reinforcing bars. To achieve this transfer, supplementary hoop reinforcement was used in the proposed design. Due to the obstruction of the existing tower legs, two half-circle hoops, connected with mechanical couplers, were employed. This required enlarging the existing caisson diameter at the location of the new cap beams (see Fig. 9). It is essential that a detailed analysis be undertaken to determine the required hoop quantity and discontinuous bar embedment length. Nonlinear finite element analyses were undertaken for these purposes. 


\section{Nonlinear Finite Element Modeling}

A two-dimensional, continuum-type, plane-stress element was used for the finite element modeling through a computer program, VecTor2 (Vecchio 2016). Other specialized analysis programs, such as ATENA (Cervenka 2016) and WCOMD (Maekawa 2016), could also be used. The constitutive model employed in VecTor2 is based on the Disturbed Stress Field Model (Vecchio 2000), which is an extension of the Modified Compression Field Theory (Vecchio and Collins 1986). This model employs a smeared, rotating crack approach within a total-load, secant-stiffness solution algorithm. Tension stiffening effects were considered within the constitutive models of the Disturbed Stress Field Model. Reinforcing bar response was modelled using an elastic-plastic response, followed by a parabolic strain hardening phase according to the Seckin model (1981). Reinforcement dowel action was also considered. Throughout the analyses, the default models were used for the material behaviours simulated as recommended by Wong et al. (2013) (see Table 3).

The only parameter required as input for the concrete modeling was the compressive strength. The modulus of elasticity $E_{c}$, the strain $\varepsilon_{0}$ corresponding to the peak stress $f^{\prime}{ }_{c}$, and the cracking stress $f_{t}^{\prime}$, were calculated by the program using the following equations (Wong et al. 2013). The reinforcing bar properties were estimated for Grade 400 reinforcement. The resulting stress-strain responses used in the analysis are shown in Fig. 10.

$$
\begin{aligned}
& E_{c}=3300 \sqrt{f_{c}^{\prime}}+6900 \cong 24,250 \mathrm{MPa} \\
& \varepsilon_{0}=\frac{f_{c}^{\prime}}{E_{c}}\left(\frac{n}{n-1}\right) \cong 1.95 \times 10^{-3} \text { where } n=0.8+\frac{f_{c}^{\prime}}{17}=2.42 \\
& f_{t}^{\prime}=0.33 \sqrt{f_{c}^{\prime}}=1.73 \mathrm{MPa}
\end{aligned}
$$


A finite element model was created using 3944 triangular elements (each with 6 degrees of freedom and $150 \mathrm{~mm}$ thickness) and 2054 nodes. The discontinuous reinforcing bars and the double-hoop reinforcement were modelled using perfectly-bonded discrete truss elements (each with two degrees of freedom at each node). The model was restrained with four hinges on one side, and the loading was applied uniformly on the other side with $0.1 \mathrm{~mm}$ displacement increments. A displacement-controlled analysis was employed to obtain the post-peak response, ductility, and failure mode. The finite element mesh is presented in Fig. 11.

In order to determine the required embedment length for the discontinuous bars, six different models were created by varying the embedment lengths: $650,550,450,350,250$, and $170 \mathrm{~mm}$ for Models 1 to 6 , respectively. The load-displacement responses and the failure loads for all six models are presented in Fig. 12. The responses of Models 1 to 5 exhibited similar behaviours: an initial peak load, followed by a sudden drop due to major cracking at the termination of the reinforcement, and a stiffening response due to the activation of the supplementary hoop reinforcement.

Analysis results indicated that the required minimum failure load of $400 \mathrm{kN}$ was achieved with an embedment length of $450 \mathrm{~mm}$ (Model 3). This model exhibited a ductile response governed by the yielding of the supplementary hoop reinforcement (see Fig. 13). The three stages of cracking are presented in Fig. 14.

The change in the embedment length affected the load capacity and the failure mode of the caisson significantly. The crack patterns for all models at failure are presented in Fig. 15. An embedment length of $250 \mathrm{~mm}$, which is recommended by the adhesive manufacturer, resulted in an undesirable failure mode involving the local failure of concrete (see Fig. 15, Model 5). The hoop steel was partially effective, and increased the load capacity by only $11 \%$ beyond the first 
peak load (as compared to $55 \%$ in Model 1). The failure load obtained was $250 \mathrm{kN}$, which is significantly lower than the required value of $400 \mathrm{kN}$. An embedment length of $170 \mathrm{~mm}$, which is less than the length recommended by the adhesive manufacturer, resulted in a brittle failure upon first cracking at an applied load of $200 \mathrm{kN}$. This failure was the result of disintegration of the concrete at the edge (see Fig. 15, Model 6). The hoops were ineffective in this model and did not provide any increase in the load capacity. Note that the analysis uses perfectly bonded bars; a possible bond slip may accompany this failure, making it even more undesirable.

\section{Summary and Conclusions}

Many existing self-supporting towers rely on caisson foundations for uplift resistance. Increased demand for cellular antenna towers and public opposition to new towers in urban centres, have driven the addition of antennas on existing towers. This increase in loads and more stringent strength requirements in recent updates to design standards have required strengthening of many existing caisson foundations. Although a number of retrofit schemes are commonly used in practice, there is a lack of published guidelines for the proper analysis and design of the retrofitted foundation systems. In this study, an analysis and design methodology was presented for the strengthening of reinforced concrete caisson foundations for large uplift loads. Strut-andtie models were developed to verify the overall strength and integrity. Nonlinear finite element analyses were undertaken to assess the performance and the failure mode at the micro level. The proposed methodology was introduced with a case study involving an existing self-supporting tower. The developed design drawings and construction pictures were also presented. The results of the studies conducted support the following conclusions: 
1. The addition of new structural elements is required to significantly increase the uplift capacity of existing caisson foundations.

2. The capacity and behaviour of the retrofitted foundation must be verified by a numerical analysis. The analysis must demonstrate that the connections between the new elements and existing foundations are adequate to transfer the load.

3. A proper analysis method must be employed for deep beams using the strut-and-tie methods and nonlinear finite element analyses. Simple sectional analysis methods with simply-supported slender beam approaches are not valid for deep beams.

4. Special attention must be paid to the reinforcement development for deep members, including simple support points. An overhang beyond the support points is required to develop the reinforcing bars. T-headed bars or welded plates may also be employed if there is limited space for such a beam overhang.

5. Providing the recommended bond development length for epoxy anchored bars does not ensure that the bar tension can safely be carried. The designer must ensure that there are adjacent rebars available (or designed) to transfer the tension load of the terminated bars to a support point or other reinforcing bars.

6. Proper crack control reinforcement must be provided to ensure the long term durability of deep beams. This typically requires using an orthogonal grid of reinforcing bars near each face of deep beams.

7. The analysis and design process must be repeated for all possible load cases. Even though the new elements are designed for uplift loads, they may be subjected to significant compression loads due to load sharing. 
8. The analysis and design methodology proposed in this study was numerically shown to increase the uplift capacity of an existing caisson by a factor of 2.1. Overall behaviour, ductility, and the failure mode of the retrofitted system were found to be satisfactory.

9. The proposed design has a general applicability and is suitable for applications where there is limited space around the existing caissons. 


\section{Acknowledgements}

The authors would like to thank Mr. Zane Biblow for his contributions to an earlier version of the design proposed in this study. The authors would also like to acknowledge the contribution of Sálvio Aragão Almeida Júnior, an undergraduate summer student funded by the Science Without Borders Scholarship Program, for assisting in the finite element analyses presented in this paper. 


\section{References}

Abdalla, H.A. 2002. Assessment of damages and repair of antenna tower concrete foundations. Construction and Building Materials. 16(8): 527-534.

Bruneau, M., Magued, M.H., and Dryburgh, R.B. 1989. Recommended guidelines for upgrading existing towers. Canadian Journal of Civil Engineering. 16(5): 733-742.

Cervenka, V. 2016. ATENA: Software for nonlinear analysis of reinforced concrete structures [online]. Prague, Czech Republic. Available from http://www.cervenka.cz [accessed 18 January 2016].

CSA. 2014. Design of concrete structures. CSA standard CSA A23.3. Canadian Standards Association (CSA). Mississauga, ON, Canada. 290 pp.

CSA. 2013. Antennas, towers, and antenna-supporting structures. CSA standard S37-13. Canadian Standards Association (CSA). Mississauga, ON, Canada. 216 pp.

CSA. 2001. Antennas, towers, and antenna-supporting structures. CSA standard S37-01. Canadian Standards Association (CSA). Mississauga, ON, Canada. 118 pp.

CSA. 1994. Antennas, towers, and antenna-supporting structures. CSA standard S37-94. Canadian Standards Association (CSA). Mississauga, ON, Canada. 105 pp.

Faridafshin, F., and McClure, G. 2008. Seismic response of tall guyed masts to asynchronous multiple-support and vertical ground motions. ASCE Journal of Structural Engineering. 134(8): 1374-1382.

Kumalasari, C., Ding, Y., Madugula, M.K.S., and Ghrib, F. 2006. Compressive strength of solid round steel members strengthened with rods or angles. Canadian Journal of Civil Engineering. 33(4): 451-457. 
Maekawa, K. 2016. WCOMD: Nonlinear analysis program of reinforcement concrete structures [online]. University of Tokyo, Japan. Available from http://www.forum8.co.jp/english/ucwin/wcomd-e.htm [accessed 18 January 2016].

Magued, M.H., Bruneau, M., and Dryburgh, R.B. 1989. Evolution of design standards and recorded failures of guyed towers in Canada. Canadian Journal of Civil Engineering. 16(5): 725732.

Seckin, M. 1981. Hysteretic behavior of cast-in-place exterior beam-column-slab assemblies. Ph.D. thesis, Department of Civil Engineering, University of Toronto, ON, Canada. Selby, R.G., and Dryburgh, R.B. 1996. A comparison of the gust factor method and the patch load method of analysis of guyed towers. Canadian Journal of Civil Engineering. 23(4): 862871.

Tjhin, T., and Kuchma, D. 2004. CAST: Computer-aided strut and tie analysis software. Version 0.9.11. University of Illinois at Urbana-Champaign, IL, USA.

Vecchio, F.J. 2016. VecTor2: Nonlinear finite element analysis software for reinforced concrete structures [online]. Version 2.9. University of Toronto, ON, Canada. Available from http://www.civ.utoronto.ca/vector/ [accessed 18 January 2016].

Vecchio, F.J. 2000. Disturbed stress field model for reinforced concrete: formulation. ASCE Journal of Structural Engineering. 126(8): 1070-1077.

Vecchio, F.J., and Collins, M.P. 1986. The modified compression field theory for reinforced concrete elements subject to shear. ACI Structural Journal. 83(2): 219-231.

Wahba, Y.M.F., Madugula, M.K.S., and Monforton, G.R. 1994. Limit states design of antenna towers. Canadian Journal of Civil Engineering. 21(6): 913-923. 
Wong P.S., Vecchio F.J., and Trommels, H. 2013. VecTor2 and FormWorks user's manual. Technical Report, Department of Civil Engineering, University of Toronto, ON, Canada. 
Table 1. Geotechnical resistance factor, $\varphi$, for constant-width caissons.

\begin{tabular}{c|c|c|c} 
& S37-94 & S37-01 & S37-13 \\
\hline $\boldsymbol{\varphi}$ & 0.75 & 0.375 & 0.5 \\
\hline Utilization & $100 \%$ & $200 \%$ & $150 \%$
\end{tabular}


Table 2. Strength reduction parameters and material properties.

\begin{tabular}{c|ccc|c}
$\begin{array}{c}\text { Concrete } \\
\text { Struts }\end{array}$ & 0.85 & & $f_{c}^{\prime}(\mathrm{MPa})$ & 30 \\
\hline Steel Ties & $1.00 \varphi_{c}$ & & $f_{y}(\mathrm{MPa})$ & 400 \\
\hline CCC Nodes & $0.85 m \varphi_{c}$ & & & $A_{s}$ \\
\cline { 1 - 2 } CCT Nodes & $0.75 m \varphi_{c}$ & & $4-20 \mathrm{M}\left(\mathrm{mm}^{2}\right)$ & 1200 \\
\hline CTT Nodes & $0.65 m \varphi_{c}$ & & $5-\# 9\left(\mathrm{~mm}^{2}\right)$ & 3225
\end{tabular}


Table 3. Default material models.

\begin{tabular}{ll} 
Material Behaviour & Default Model \\
\hline Compression Base Curve & Popovics (NSC) \\
Compression Post-Peak & Modified Park-Kent \\
Compression Softening & Vecchio 1992-A \\
Tension Stiffening & Modified Bentz 2003 \\
Tension Softening & Linear \\
Confinement Strength & Kupfer / Richart \\
Concrete Dilatation & Variable - Orthotropic \\
Cracking Criterion & Mohr-Coulomb (Stress) \\
Crack Width Check & Agg/5 Max crack width \\
Concrete Hysteresis & Nonlinear w/ plastic offsets \\
Slip Distortion & Walraven \\
Rebar Hysteresis & Seckin w/ Bauschinger \\
Rebar Dowel Action & Tassios (Crack slip) \\
\hline
\end{tabular}




\section{List of Tables}

Table 1. Geotechnical resistance factor, $\varphi$, for constant-width caissons.

Table 2. Strength reduction parameters and material properties.

Table 3. Default material models.

\section{List of Figures}

Fig. 1. Loads resisted by self-supporting tower foundations.

Fig. 2. Commonly used retrofit schemes for caisson foundations overloaded in uplift.

Fig. 3. Self-supporting tower examined.

Fig. 4. Caisson foundation to be strengthened.

Fig. 5. Strut-and-tie model for uplift loads.

Fig. 6. Strut-and-tie analysis results for uplift loads.

Fig. 7. Expected cracking under compression loads in the absence of bottom reinforcing bars.

Fig. 8. Reinforcement details of the proposed design.

Fig. 9. Construction pictures of the proposed design.

Fig. 10. Concrete and reinforcement uniaxial response.

Fig. 11. Finite element model.

Fig. 12. Load and deflection results for different embedment lengths.

Fig. 13. Reinforcing bar stresses for Model 3 (in MPa).

Fig. 14. Crack patterns for Model 3: (a) at the first peak, (b) at the load drop, and (c) at failure.

Fig. 15. Crack patterns at failure for different embedment lengths. 


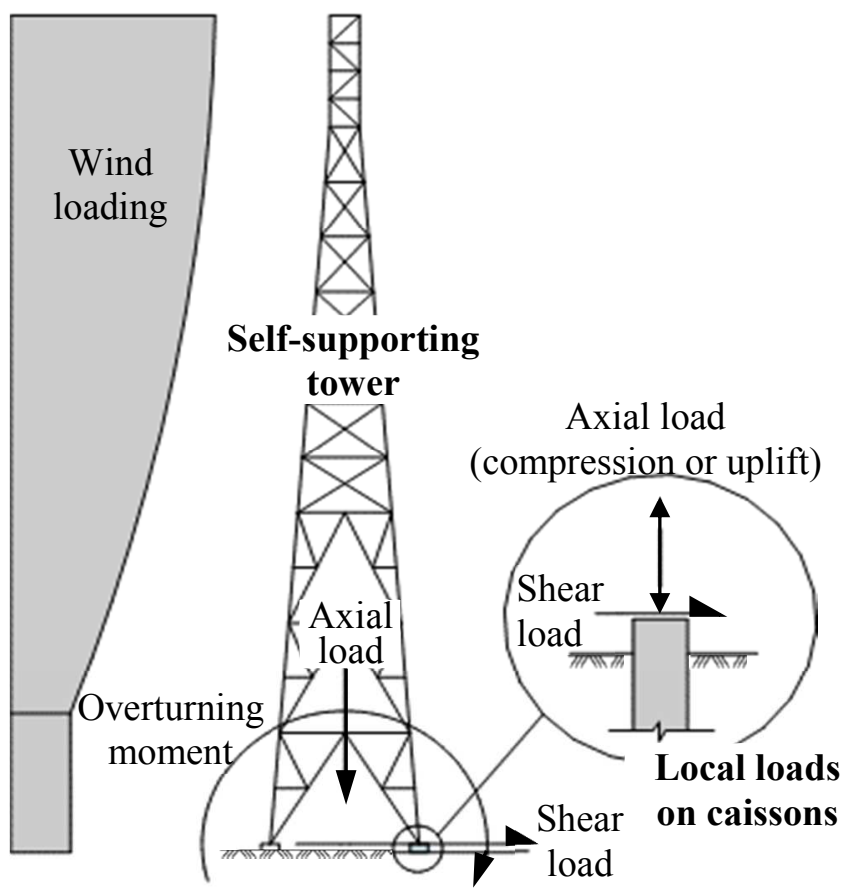




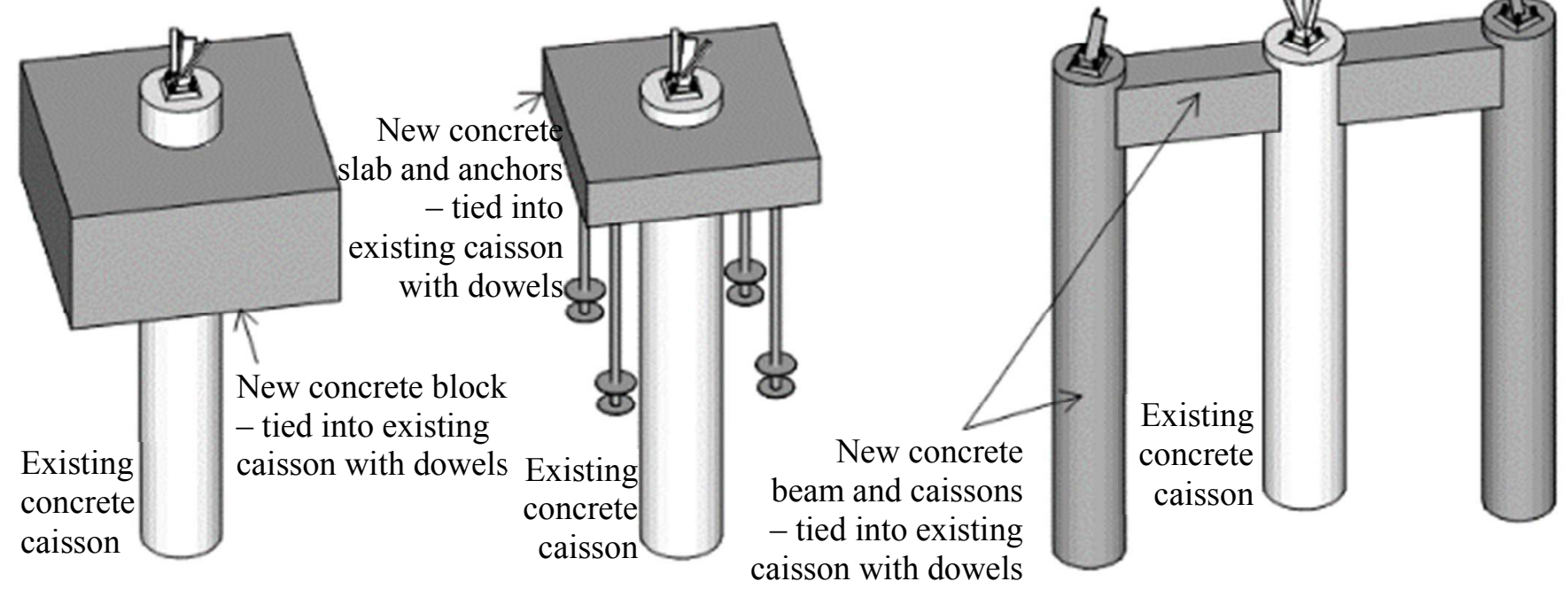




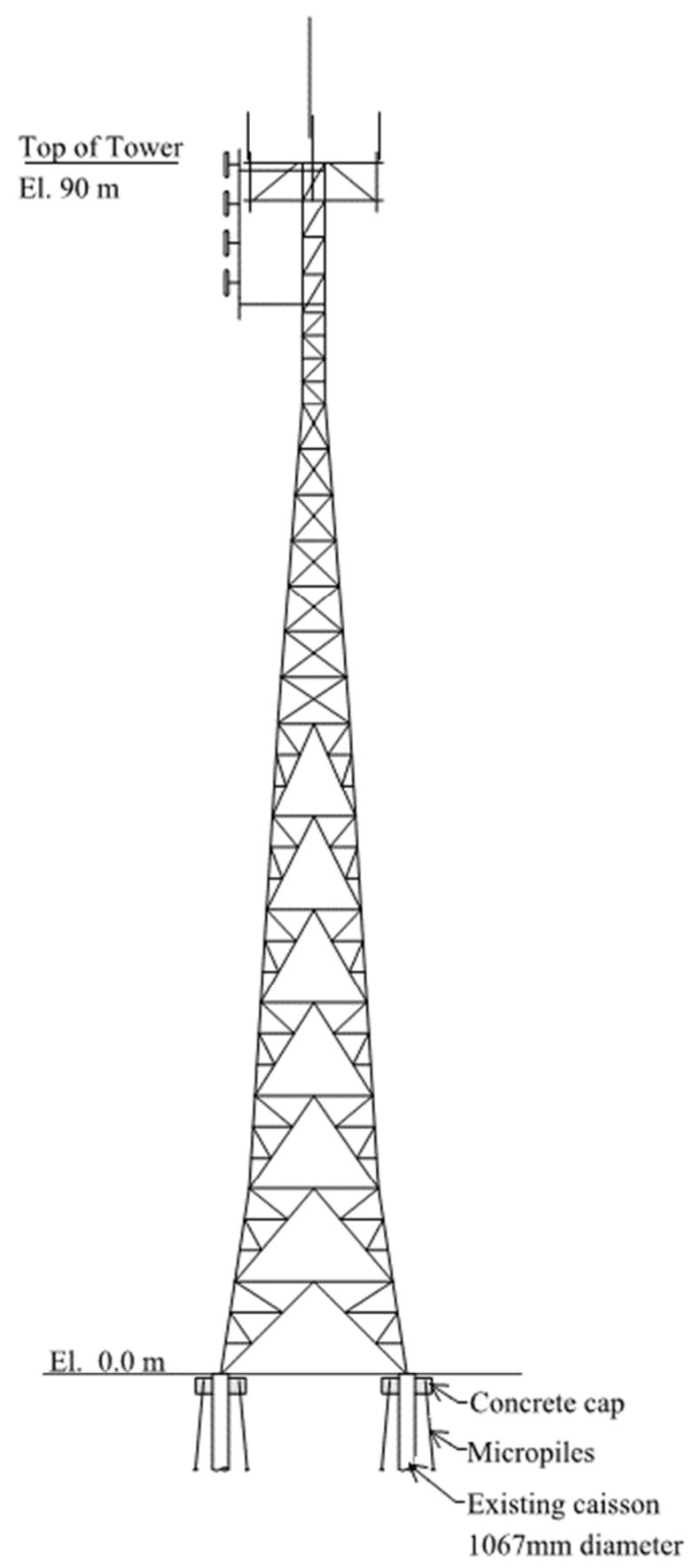




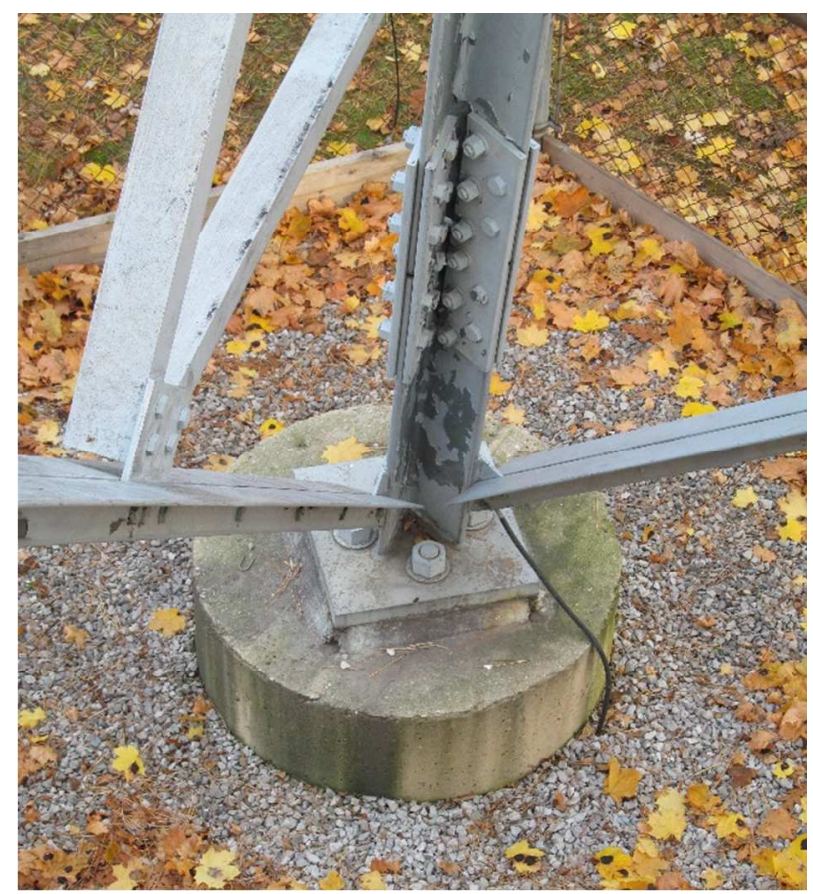

https://mc06.manuscriptcentral.com/cjce-pubs 


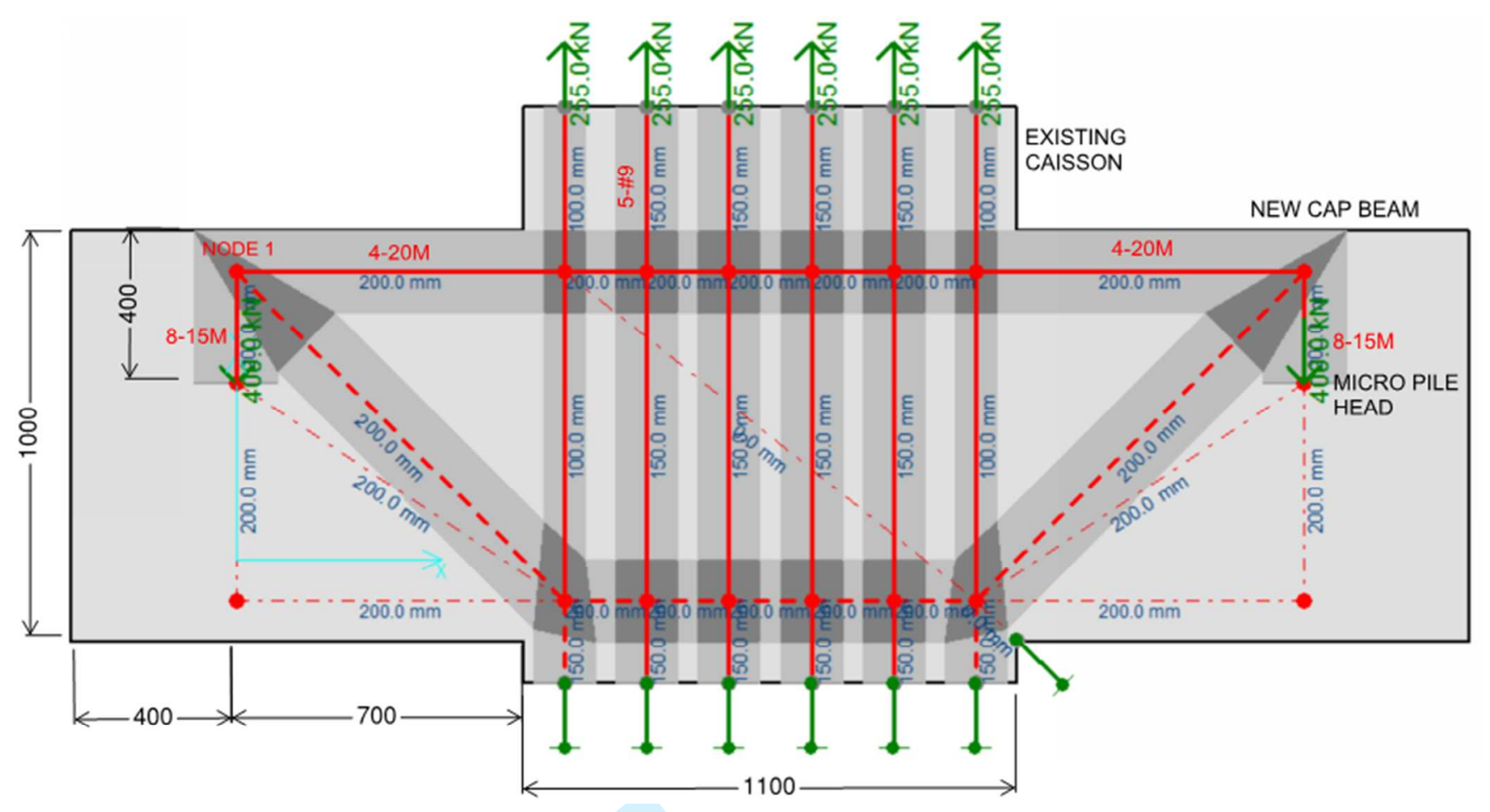




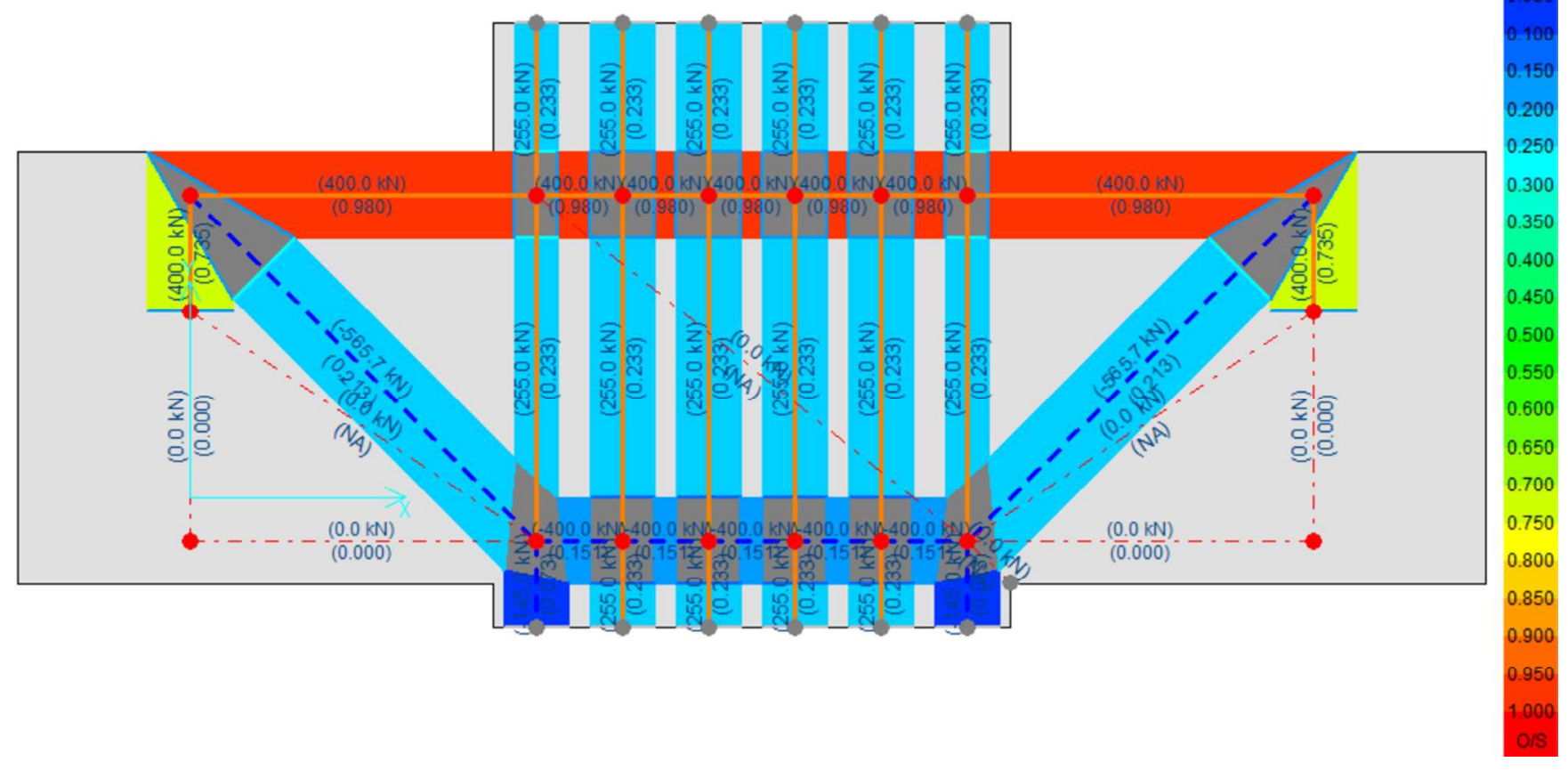




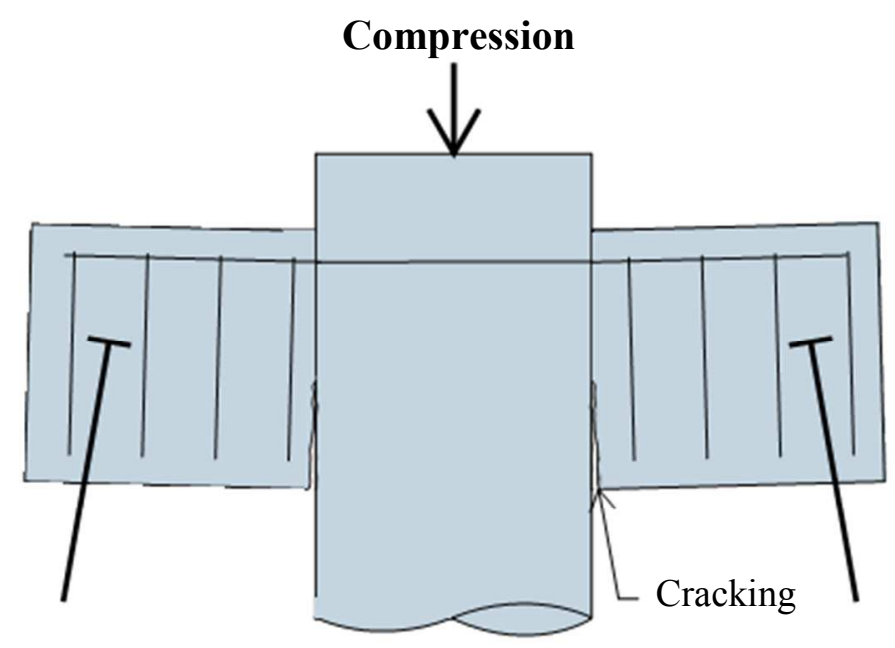

https://mc06.manuscriptcentral.com/cjce-pubs 


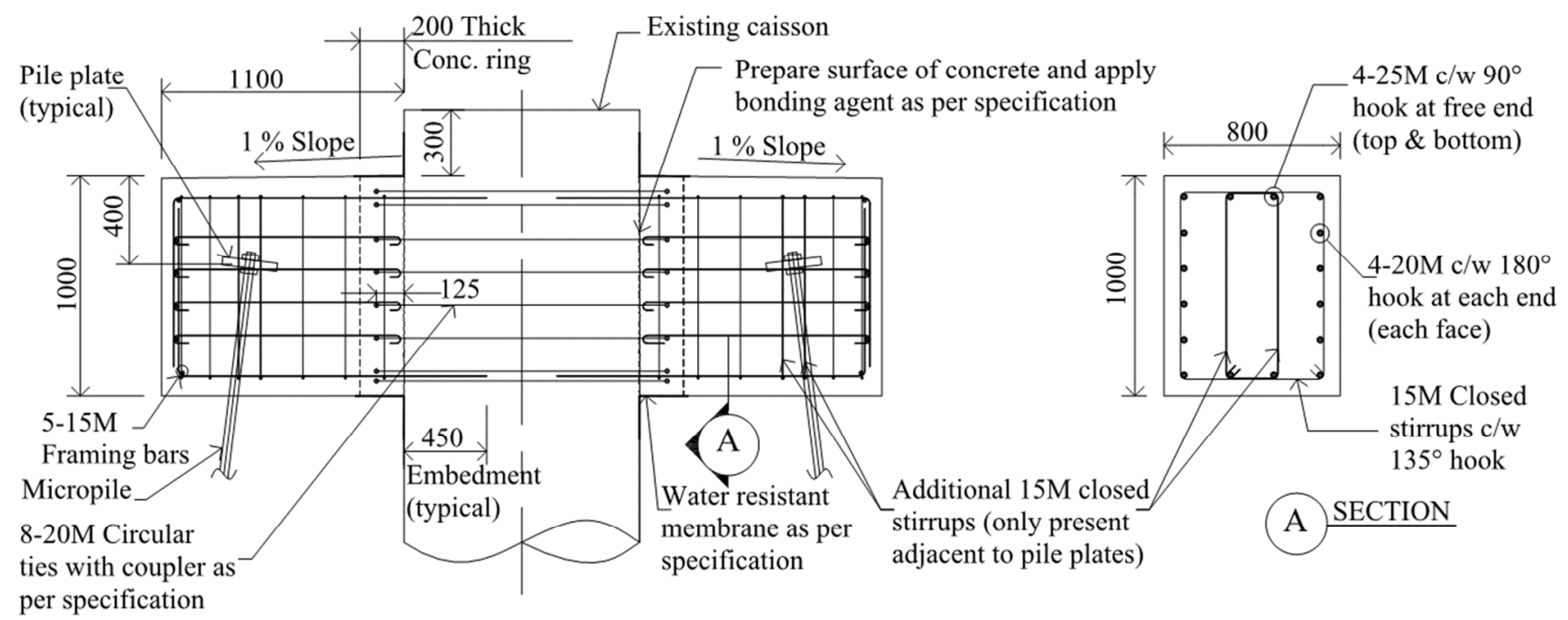



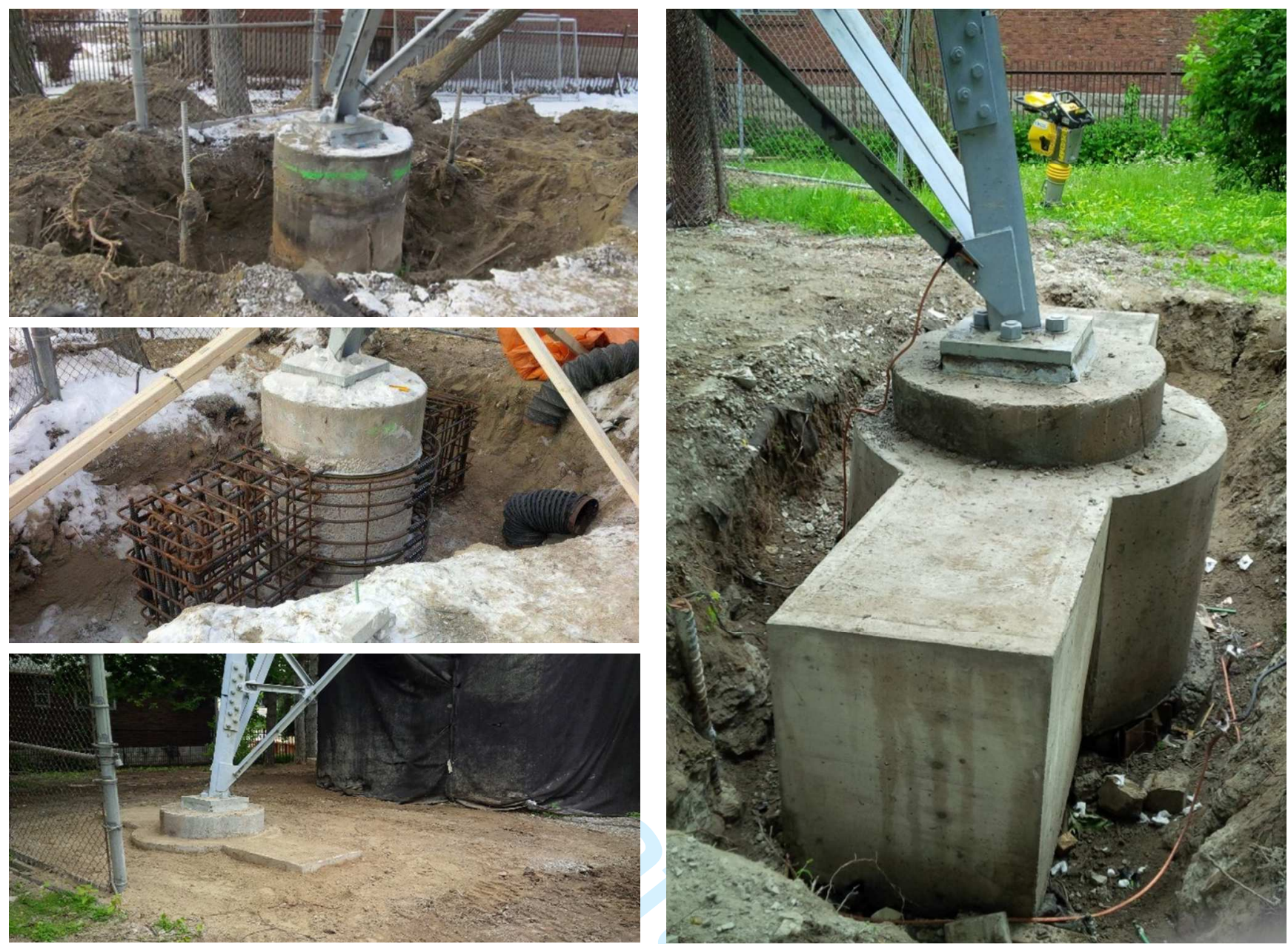

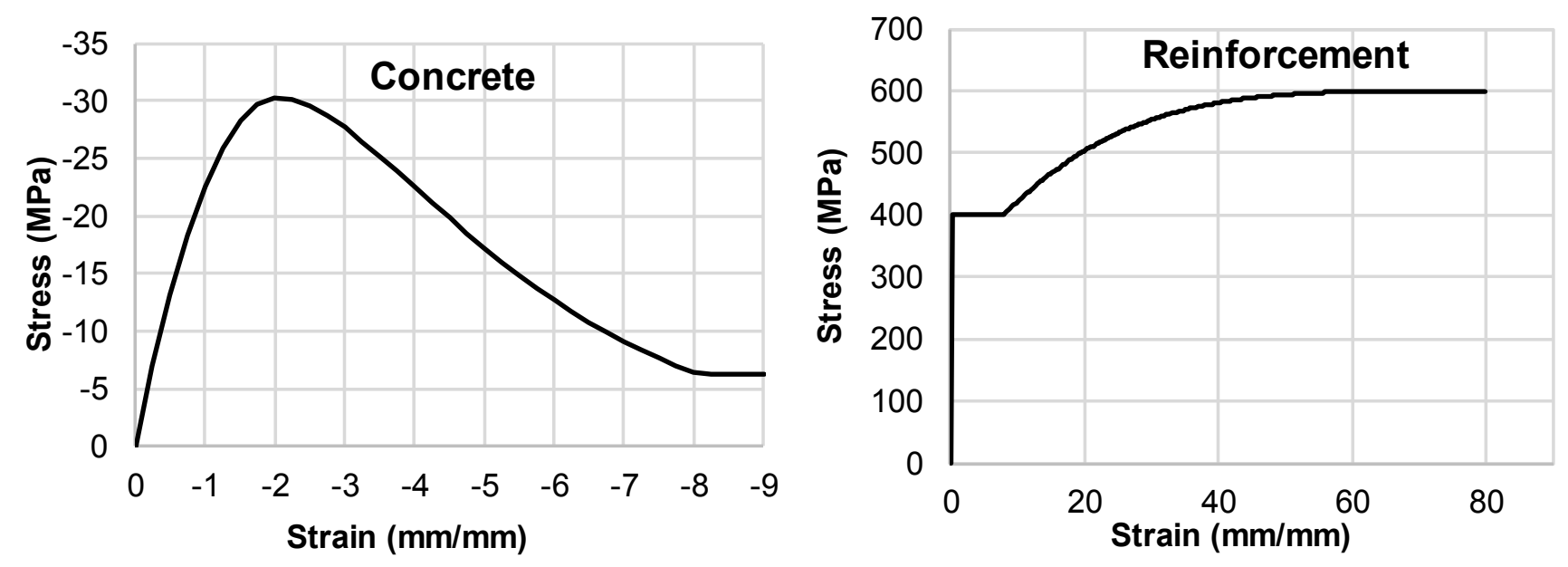


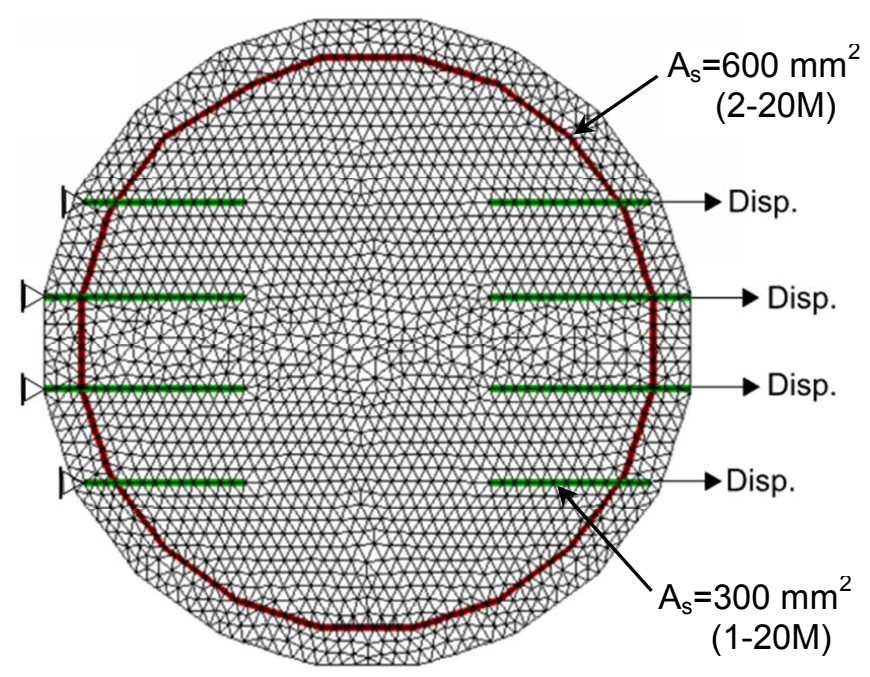

https://mc06.manuscriptcentral.com/cjce-pubs 

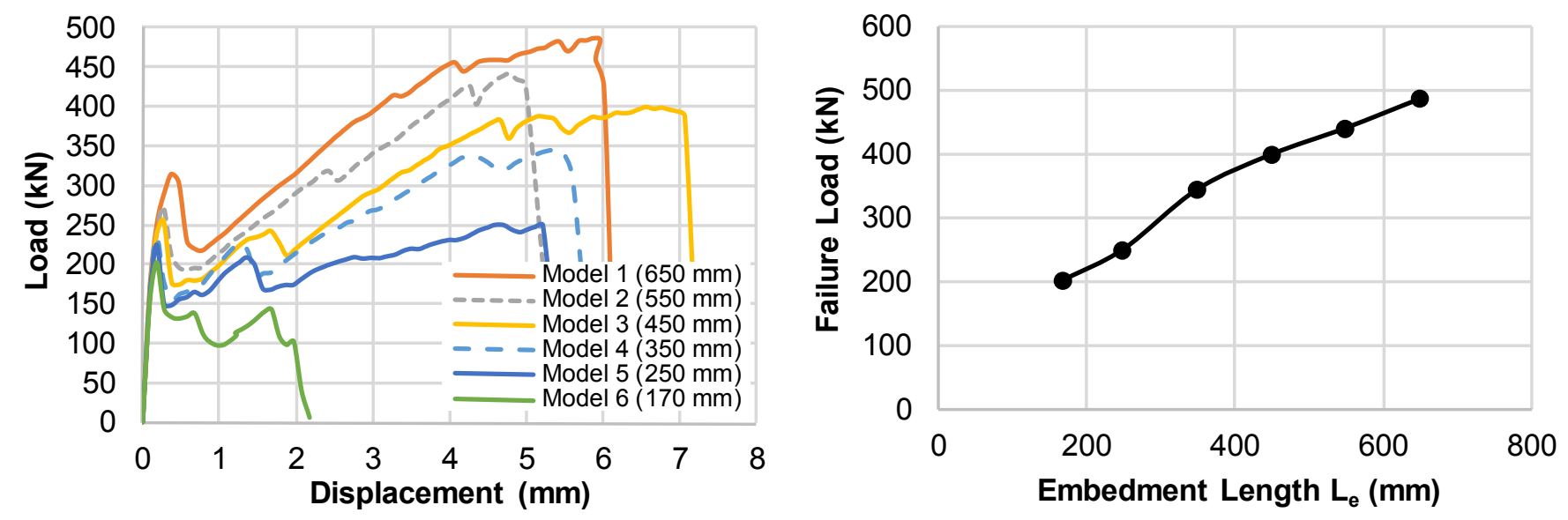

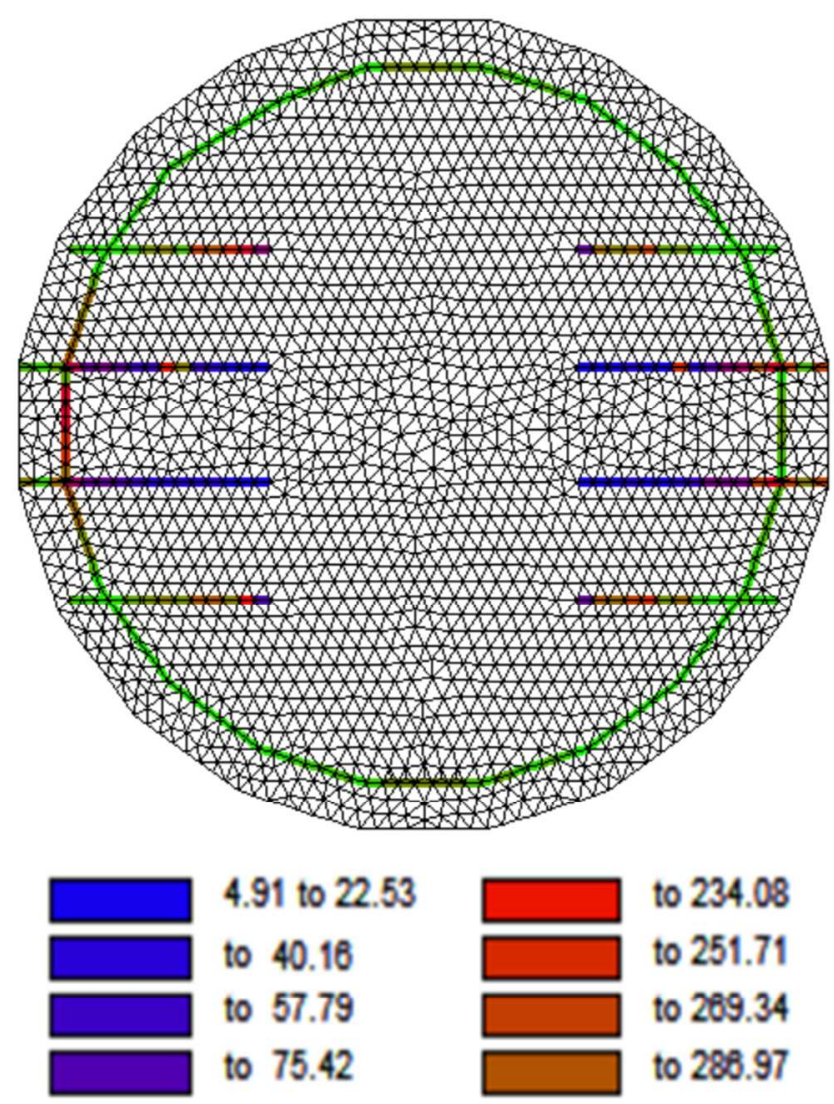

4.91 to 22.53

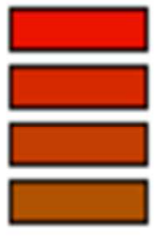

to 234.08

to 40.16

to 57.79

to 75.42

to 251.71

to 269.34

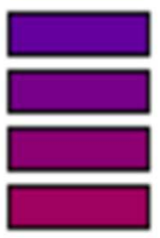

to 93.05

to 286.97

to 110.68

to 128.31

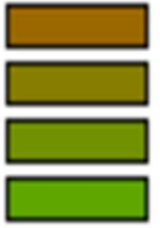

to 304.60

to 322.23

to 145.94

to 339.86

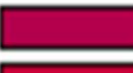

to 163.57

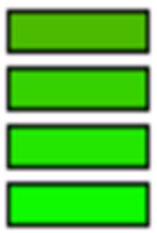

to 357.49

to 375.12

to 181.20

to 198.83

to 392.75

to 216.45

to 410.38

to 428.01 


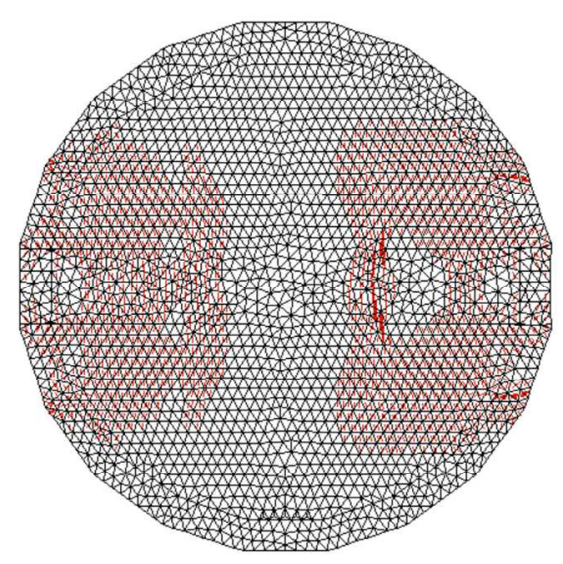

(a)

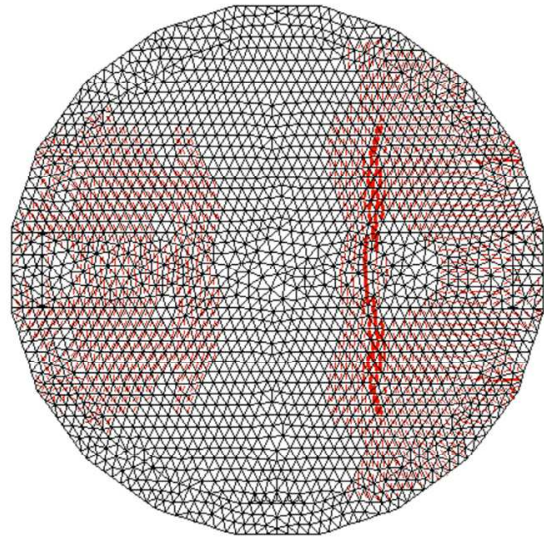

(b)

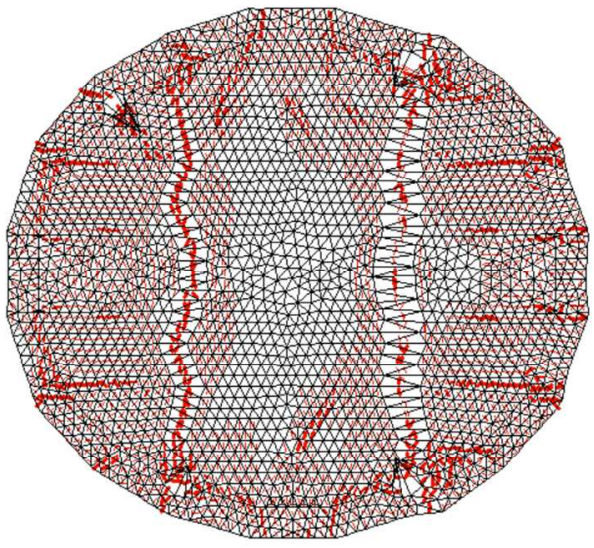

(c) 

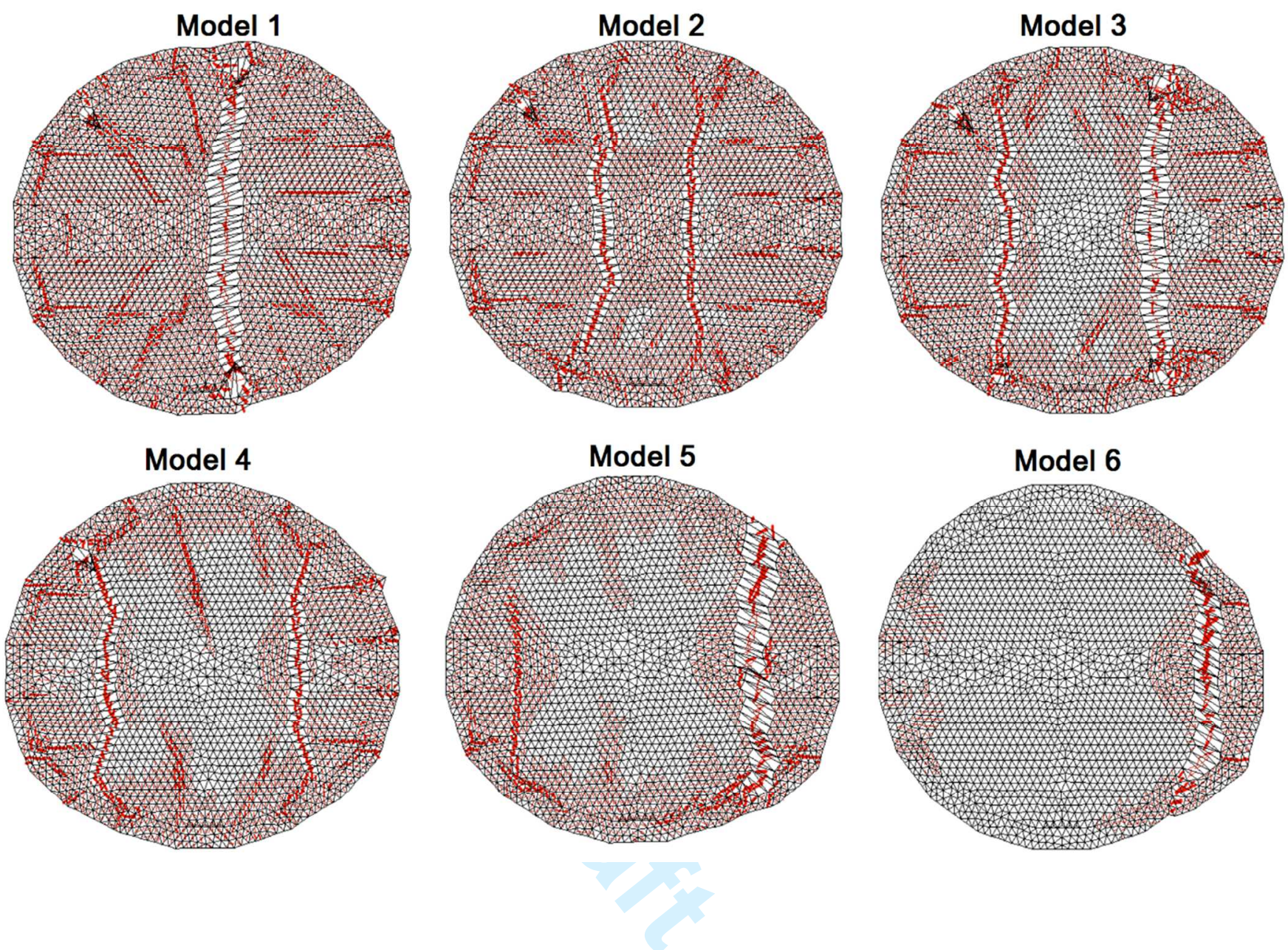